\title{
ETHNIC ATTRITION AND THE OBSERVED HEALTH OF LATER-GENERATION
}

\author{
MEXICAN AMERICANS \\ Francisca Antman, Brian Duncan, and Stephen J. Trejo*
}

January 7, 2016

\begin{abstract}
Numerous studies find that U.S.-born Hispanics differ significantly from non-Hispanic whites on important measures of human capital, including health. Nevertheless, almost all studies rely on subjective measures of ethnic self-identification to identify immigrants' U.S.-born descendants. This can lead to bias due to "ethnic attrition," which occurs whenever a U.S.-born descendant of a Hispanic immigrant fails to self-identify as Hispanic. This paper shows that Mexican American ethnic attritors are generally more likely to display health outcomes closer to those of non-Hispanic whites. This biases conventional estimates of Mexican American health away from suggesting patterns of assimilation and convergence with non-Hispanic whites.
\end{abstract}

\section{CSMGEP Session}

Session Title: Health Outcomes, Immigration, and Development

JEL Classification: J15, J12, I14

Keywords: assimilation, ethnic attrition, identity

*Antman (corresponding author): University of Colorado Boulder, Department of Economics, 256 UCB, Boulder, CO 80309, Phone (303) 492-8872, Fax (303) 492-8960, francisca.antman@colorado.edu

Duncan: University of Colorado Denver, Department of Economics, Campus Box 181, Denver, CO 80217-3364, Phone (303) 315-2041, Fax (303) 315-2048, brian.duncan@ucdenver.edu Trejo: University of Texas at Austin, Department of Economics, 2225 Speedway Stop C3100, Austin, TX, 78712-1690, Phone (512) 475-8512, Fax (512) 471-3510, trejo@ austin.utexas.edu We thank Douglas Almond, Brian Cadena, Terra McKinnish, Joseph P. Price, Fernando Riosmena, and conference participants at the American Economic Association annual meeting, Society of Labor Economists meeting and the Western Economics Association International meeting for their feedback. 
A fundamental issue in the long-running debate over immigration policy is the criticism that Hispanics are poorly assimilated. These views are supported by numerous studies which show that Hispanics often differ significantly from non-Hispanic whites on measures of human capital such as education (Smith 2003) and health (Antecol and Bedard 2006). Nevertheless, almost all studies rely on subjective measures of ethnic self-identification to identify immigrants' U.S.-born descendants. This can lead to bias due to "ethnic attrition," which occurs whenever a U.S.-born descendant of a Hispanic immigrant fails to self-identify as Hispanic. Duncan and Trejo (2011) show that since ethnic attritors are positively selected on socioeconomic status, conventional estimates of educational progress for Mexican Americans are biased downward. In this paper we investigate whether ethnic attrition can also account for some of the perceived health gaps between ethnic groups. To focus the analysis, we restrict attention to the experience of Mexicans in particular, the single largest immigrant group in the U.S., and identify ethnic attritors as individuals with at least one parent who identifies as Mexican/Mexican American, but who is not himself identified as Mexican/Mexican American. The results from comparing health outcomes across groups indicate that Mexican American ethnic attritors are generally more likely to display health outcomes closer to those of non-Hispanic whites compared with individuals who identify as Mexican Americans. This suggests that conventional estimates of Mexican American health relying solely on measures of self-identification are likely to be biased away from suggesting patterns of assimilation and convergence with non-Hispanic whites.

The remainder of this paper proceeds as follows. Section I describes the data used in the analysis, Section II presents the results comparing health outcomes of self-identified Mexicans, ethnic attritors, and non-Hispanic whites, and Section III concludes.

\section{DATA}


The data we use come from the 2000-2014 waves of the National Health Interview Survey (NHIS), the major source of detailed data on a broad range of health outcomes and related characteristics of the U.S. population. Since the NHIS does not have direct information on country of birth outside the U.S., we restrict our sample to children, ages $0-17$, living with both of their parents, so that we may connect ethnic self-identification of parents with their children. ${ }^{1}$ Thus, Mexican ethnic attritors are defined in this study as those individuals who are not identified as Mexican/Mexican Americans, despite the fact that they have at least one parent who ethnically self-identifies as Mexican/Mexican American. We follow standard definitions used in the literature to describe immigrant generation. "1.5" generation children are foreign-born children with at least one foreign-born parent. ${ }^{2} 2^{\text {nd }}$ generation children are U.S.-born children with at least one foreign-born parent. $3^{\text {rd }}+$ generation children are U.S.-born individuals who have two U.S.born parents. Since the focus of this paper is on Mexican/Mexican American immigrants and their descendants, all $1.5,2^{\text {nd }}$, and $3^{\text {rd }}$ generation children must have at least one parent who selfidentifies as Mexican/Mexican American. We later compare outcomes for ethnic attritors and non-attritors to those of non-Hispanic white children, defined as $3^{\text {rd }}+$ generation children who are "white only" and whose parents are also non-Hispanic "white only."

While the NHIS collects a wide variety of health outcomes, we focus here on those outcomes less likely to be subject to endogeneity concerns surrounding diagnosis. For instance, individuals with higher socioeconomic status may have better access to health care and thus may be more likely to report a bad diagnosis. The most objective of these health measures are indicators

\footnotetext{
${ }^{1}$ See Antman, Duncan, and Trejo (2015) for an analysis using the Current Population Survey, which allows us to exploit information on parental place of birth, but has fewer health outcomes to explore.

${ }^{2}$ These might also be described as first generation immigrants, but we use the term " 1.5 generation," as others have done, to emphasize that they arrived as children.
} 
that the child had low birth weight and is currently obese, respectively. ${ }^{3}$ Finally, to make use of the extensive health data available in the NHIS, we also report results from variables indicating a child had at least one health condition reported at the time of the survey and a separate indicator for whether the child had an activity limitation. ${ }^{4}$ To compare our findings with others in the literature, we also report the results from a binary indicator for poor self-rated health (SRH), the results of a question asking whether the respondent considers the sampled child's health to be poor or fair, as compared with good, very good, or excellent. We follow the literature in defining this "poor health" indicator to be equal to 1 if the sampled individual is reported to be in poor or fair health. While some may be concerned about the subjective nature of self-rated health, an extensive literature suggests that SRH captures an important dimension of health, even beyond other measures (Idler and Benyamini 1997).

Although the NHIS has several survey modules that relate to children's health, not all health questions are asked of all children in the sample. In particular, detailed information on health outcomes is only collected in the "child sample" survey which consists of one randomly selected child from each household. Further, information on weight and height to construct the obesity measure used here are only collected for children between the ages of 12 and 17 in more recent waves of the survey. Finally, we note that since our analysis focuses on children, and the NHIS requires respondents to be household members who are at least 18 years of age, none of the

\footnotetext{
${ }^{3}$ Low birth weight is classified as having birth weight below 2,500 g. Obese children have a body mass index (BMI) greater than or equal to the sex- and age-specific $95^{\text {th }}$ percentile from the 2000 CDC Growth Chart.

${ }^{4}$ The list of health conditions include: autism, Asperger's, down syndrome, cerebral palsy, muscular dystrophy, cystic fibrosis, sickle cell anemia, diabetes, arthritis, congenital heart disease, other heart condition, asthma, hay fever, respiratory allergy, food/digestive allergy, eczema/skin allergy, frequent diarrhea/colitis, anemia, ear infections, seizure, frequent headaches/migraines, stutter/stammer, trouble seeing, and an impairment/health problem that limited their ability to run/walk/play. An activity limitation is a limitation in activity due to a chronic health condition, related to the following list of health conditions: vision/problem seeing, hearing problem, speech problem, asthma/breathing problem, birth defect, injury, intellectual disability, other developmental problem (e.g., cerebral palsy), other mental, emotional, or behavioral problem, bone, joint, or muscle problem, epilepsy or seizures, learning disability, attention deficit/hyperactivity disorder (ADD/ADHD), or other impairment problem.
} 
individuals in our sample are responding for themselves. While this may raise questions about whether child ethnic self-identification is truly captured by the survey, we argue that it is likely that parents or close relatives are responding for children and there is a high correlation between how children view themselves and how they are viewed by the survey respondent. In any case, at a minimum, our estimate of ethnic attrition is likely to be an underestimate of the degree of ethnic attrition we might expect if we solicited this information from the children sampled in later years when they have separated from their parents and formed their own households.

\section{[TABLE 1 HERE]}

\section{RESULTS}

Table 1 documents the extent of ethnic attrition in our sample by linking whether children are identified as Mexican American with whether one or both parents identify as Mexican/Mexican American. As such, it also links the concept of ethnic attrition of children with the intermarriage rates of parents, which is much more common for children at the $3^{\text {rd }}+$ generation. For all groups of children $\left(1.5,2^{\text {nd }}\right.$, and $3^{\text {rd }}+$ generations $)$, those with both parents identified as Mexican/Mexican American are almost universally identified as Mexican themselves with rates of ethnic identification higher than 99 percent. In contrast, children of intermarried parents are far less likely to be identified as Mexican, with rates of identification around 60 to 70 percent. $^{5}$ This implies ethnic attrition rates of 30 to 40 percent for children of intermarried parents. Thus, intermarriage itself is closely linked with ethnic attrition. Since intermarriage rates are highest for the parents of $3^{\text {rd }}+$ generation children (almost 45 percent) versus intermarriage rates for parents of 1.5

\footnotetext{
${ }^{5}$ This result is strongly consistent with analysis of ethnic attrition rates and intermarriage rates from the Current Population Survey where ethnic identification can be defined using measures of birthplace (Antman, Duncan and Trejo 2015). This suggests that the ethnic attrition measure we construct here relying on self-identification of parents is broadly consistent with measures relying on birthplace or ancestry.
} 
generation children ( 2 percent) and $2^{\text {nd }}$ generation children (10 percent), it is understandable that ethnic attrition is far higher for children at the $3^{\text {rd }}+$ generation. This is shown at the bottom of the table, where Mexican identification rates for children at the $3^{\text {rd }}$ and higher generation are 85.85 percent versus over 95 percent for the 1.5 and $2^{\text {nd }}$ generation children. This implies that ethnic attrition rates are 14.15 percent (100-85.85) for $3^{\text {rd }}$ generation children and below 5 percent for 1.5 and $2^{\text {nd }}$ generation children. This justifies the focus of our analysis on $3^{\text {rd }}+$ generation children, which we turn to in Table 2 .

\section{[TABLE 2 HERE]}

Table 2 compares the health outcomes of ethnic attritors with those of individuals identified as Mexican/Mexican American at the $3^{\text {rd }}+$ generation, as well as with those of non-Hispanic whites. In general, we find a pattern which suggests that ethnic attritors more closely resemble non-Hispanic whites on measures of health. For example, 0.88 percent of both the group of Mexican ethnic attritors and non-Hispanic whites are reported to be in poor health, resulting in a .002 percentage point gap between the two groups (row 5). In contrast, 1.59 percent of children identified as Mexican are reported to be in poor health, resulting in a 0.71 percentage point gap with non-Hispanic whites that is statistically significant at the 1 percent level (row 4). Thus, it comes as no surprise that the gap between attritors and non-attritors (row 6) is also 0.71 percentage points and statistically significant at 1 percent level.

Looking across other outcomes also confirms that ethnic attritors more closely resemble non-Hispanic whites on measures of health: 7.68 percent of children identified as Mexican had low birth weight, compared with 6.97 percent of non-Hispanic whites and 6.81 percent of ethnic attritors. Similarly, 14.65 percent of children identified as Mexican are obese, compared with 10.38 percent of non-Hispanic whites and 13.19 percent of ethnic attritors. While these more 
objective measures suggest that children identified as Mexican are more likely to be in worse health than non-Hispanic whites and ethnic attritors, the reverse pattern is suggested by the remaining outcomes related to reported health conditions and activity limitations. Here, the analogous statistics are 39.63 and 5.73 for children identified as Mexican, 41.85 and 6.57 for nonHispanic whites, and 44.08 and 6.01, respectively, for ethnic attritors. The latter two sets of results, although somewhat surprising, may be consistent with the difficulties surrounding using measures of diagnosed health conditions that may reflect access to health care. Regardless, these findings are consistent with the overall results emphasized here that ethnic attritors are generally closer to non-Hispanic whites on measures of health compared with individuals identified as Mexican.

Row 7 shows that adding controls for child's gender, child's integer age fixed effects, a quadratic function of mother's and father's age, mother's and father's education fixed effects, region fixed effects, and year fixed effects does not change the overall pattern of gaps between non-attritors and attritors presented in row 6 . This suggests that the results are robust to concerns that differences in health outcomes across ethnic attritors and non-attritors are being driven purely by differences in socioeconomic status. While not all gaps are statistically significant, it is also telling that the differences between individuals identified as Mexican and non-Hispanic whites are all statistically significant (row 4), while those between ethnic attritors and non-Hispanic whites are smaller in magnitude and not statistically significant (row 5). This also suggests that ethnic attritors are closer to non-Hispanic whites on measures of health compared with individuals identified as Mexican.

Row 8 summarizes the results by showing the gap between non-attritors and attritors relative to the gap between individuals identified as Mexican and non-Hispanic whites ([row 2 row 3$] /[$ row $2-$ row 1$]=$ row $6 /$ row 4$)$. Thus, it provides a measure of how much closer to the 
non-Hispanic white health measures are Mexican attritors relative to those who are identified as Mexican. For example, because there is essentially no gap between Mexican ethnic attritors and non-Hispanic whites with respect to poor self-related health, Mexican attritors are 100 percent closer to non-Hispanic whites relative to individuals identified as Mexican (0.71/0.71). The analogous ratios for the low birth weight, obese, health condition, and activity limitation outcomes are 123, 34.2, 200.1, and 33.6 percent, respectively. The fact that all entries in row 8 are positive shows that for all outcomes, attritors are closer to non-Hispanic whites than are individuals identified as Mexican.

\section{CONCLUSION}

This paper has investigated the differences in health outcomes across groups of Mexican ethnic attritors, non-attritors, and non-Hispanic whites. The evidence suggests that ethnic attritors display health outcomes closer to non-Hispanic whites and away from individuals that identify as Mexican. These results are strongly consistent with further work using additional data sources containing information on parent's and grandparent's place of birth to identify ethnic attrition (Antman, Duncan, and Trejo 2015). As implied by the results here, explicit estimates of the bias introduced by ethnic attrition indicate that conventional estimates of Mexican American health are likely to be biased away from suggesting patterns of assimilation and convergence with nonHispanic whites. 


\section{REFERENCES}

Antecol, Heather and Kelly Bedard. 2006. "Unhealthy Assimilation: Why Do Immigrants Converge to American Health Status Levels?” Demography, 43(2): 337-60.

Antman, Francisca Brian Duncan, and Stephen J. Trejo. 2015. "Ethnic Attrition, Assimilation, and the Measured Health Outcomes of Mexican Americans.” Unpublished Manuscript, University of Colorado.

Duncan, Brian and Stephen J. Trejo. 2011. "Intermarriage and the Intergenerational Transmission of Ethnic Identity and Human Capital for Mexican Americans." Journal of Labor Economics, 29(2): 195-227.

Idler, Ellen L. and Yael Benyamini. 1997. "Self-Rated Health and Mortality: A Review of Twenty-Seven Community Studies.” Journal of Health and Social Behavior, 38(1): 2137.

Smith, James P. 2003. "Assimilation Across the Latino Generations." American Economic Review, 93(2): 315-19. 
Table 1: Mexican Identification of Children with a Mexican Origin

\begin{tabular}{|c|c|c|c|}
\hline & \multicolumn{3}{|c|}{ Mexican Generation } \\
\hline & 1.5 & $2^{\text {nd }}$ & $3^{\mathrm{rd}}+$ \\
\hline \multicolumn{4}{|l|}{ Percent with: } \\
\hline Mexican on both sides of the family & 97.97 & 89.91 & 55.05 \\
\hline Mexican on one side of the family & 2.03 & 10.09 & 44.95 \\
\hline Total & 100.00 & 100.00 & 100.00 \\
\hline \multicolumn{4}{|l|}{ Percent identified as Mexican: } \\
\hline Mexican on both sides of the family & $\begin{array}{c}99.59 \\
(0.08)\end{array}$ & $\begin{array}{c}99.32 \\
(0.05)\end{array}$ & $\begin{array}{c}99.38 \\
(0.09)\end{array}$ \\
\hline Mexican on one side of the family & $\begin{array}{c}68.38 \\
(4.32)\end{array}$ & $\begin{array}{c}59.45 \\
(0.82)\end{array}$ & $\begin{array}{c}69.28 \\
(0.61)\end{array}$ \\
\hline All & $\begin{array}{c}98.96 \\
(0.13)\end{array}$ & $\begin{array}{c}95.30 \\
(0.11)\end{array}$ & $\begin{array}{c}85.85 \\
(0.31)\end{array}$ \\
\hline Sample size & 5,754 & 35,499 & 12,818 \\
\hline \multicolumn{4}{|c|}{$\begin{array}{l}\text { Source: } 2000-2014 \text { National Health Interview Survey (NHIS). } \\
\text { Note: Standard errors are shown in parentheses. The sample includes children ages 0-17 living with } \\
\text { both biological parents, at least one of which lists a Mexican/Mexican-American origin. 1.5 } \\
\text { generation Mexican children are foreign born children with at least one foreign born parent. 2nd } \\
\text { generation Mexican children are U.S. born children with at least one foreign born parent. 3rd+ } \\
\text { generation Mexican children are U.S. born with two U.S.-born parents. }\end{array}$} \\
\hline
\end{tabular}


Table 2: Health Measures of 3rd+ Generation Children

1. Non-Hispanic White

Sample Size

3rd+ generation Mexican:

2. Child identified as Mexican

3. Child not identified as Mexican (Mexican Ethnic Attritors)

Sample Size

Differences:

4. Identified as Mexican (2) - Non-Hispanic White (1)

5. Mexican Attritors (3) - Non-Hispanic White (1)

6. Identified as Mexican (2) - Mexican Attritors (3) (or $(4)-(5)$ )

7. Identified as Mexican (2) - Mexican Attritors (3) (with controls)

8. How much closer to the non-Hispanic white health measures are Mexican attritors relative those identified as Mexican (in percent)?

\begin{tabular}{|c|c|c|c|c|}
\hline $\begin{array}{l}\text { Poor } \\
\text { Health }\end{array}$ & $\begin{array}{l}\text { Low Birth } \\
\text { Weight }^{1}\end{array}$ & Obese $^{1,2}$ & $\begin{array}{c}\text { Health } \\
\text { Condition }^{1}\end{array}$ & $\begin{array}{c}\text { Activity } \\
\text { Limitation }\end{array}$ \\
\hline $\begin{array}{l}.88 \\
(.03)\end{array}$ & $\begin{array}{l}6.97 \\
(.12)\end{array}$ & $\begin{array}{l}10.38 \\
(.38)\end{array}$ & $\begin{array}{l}41.85 \\
(.22)\end{array}$ & $\begin{array}{l}6.57 \\
(.08)\end{array}$ \\
\hline 98,776 & 46,668 & 6,599 & 48,294 & 98,776 \\
\hline
\end{tabular}

$\begin{array}{ccccc}1.59 & 7.68 & 14.65 & 39.63 & 5.73 \\ (.09) & (.38) & (1.37) & (.70) & (.23) \\ .88 & 6.81 & 13.19 & 44.08 & 6.01 \\ (.23) & (.88) & (3.24) & (1.66) & (.58) \\ & & & & \\ 12,818 & 5,500 & 603 & 5786 & 12,818\end{array}$

$\begin{array}{lllcc}0.71^{* * * *} & 0.71^{*} & 4.27^{* * *} & -2.22^{* * *} & -0.84^{* * *} \\ (0.10) & (0.39) & (1.42) & (0.74) & (0.25)\end{array}$

$\begin{array}{lllll}0.002 & -0.16 & 2.81 & 2.23 & -0.56\end{array}$

$\begin{array}{lllll}(0.23) & (0.88) & (3.26) & (1.68)\end{array}$

$\begin{array}{lllll}0.71^{* * *} & 0.87 & 1.46 & -4.45^{* *} & -0.28\end{array}$

$\begin{array}{lllll}(0.25) & (0.95) & (3.52) & (1.81)\end{array}$

$\begin{array}{lllll}0.44^{*} & 0.64 & 0.33 & -5.04^{* * *} & -0.84\end{array}$

$\begin{array}{llll}(0.25) & (0.95) & (3.46) & (1.79)\end{array}$

$\begin{array}{lllll}99.7 & 123.0 & 34.2 & 200.1 & 33.6\end{array}$

Source: 2000-2014 National Health Interview Survey (NHIS). The sample includes U.S.-born children ages 0-17 living with both biological parents.

Sample further limited to: ${ }^{1}$ sample children, ${ }^{2}$ ages $12-17$ in the sample years $2008-2014$.

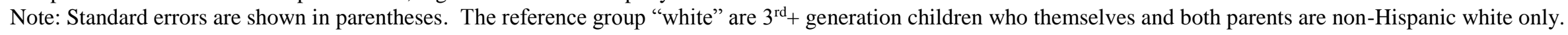

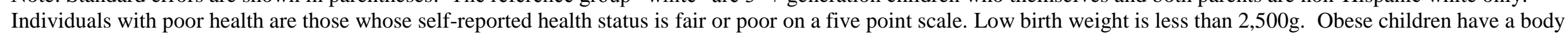

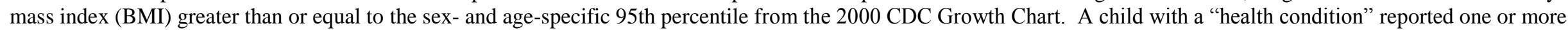

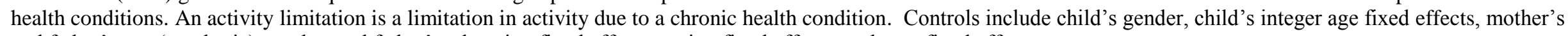
and father's age (quadratic), mother and father's education fixed effects, region fixed effects, and year fixed effects. 